\title{
Prevalence of Anemia and Knowledge Regarding Anemia among Reproductive Age Women
}

\author{
Mamta $^{1}$, L Tamphasana Devi ${ }^{2}$ \\ ${ }^{I}$ (Nursing Tutor, College of Nursing, AIIMS, Jodhpur, Rajasthan, India) \\ ${ }_{2}^{2}$ (Assistant Professor, Dr. Syamala Reddy College of Nursing, Bangalore, Karnataka, India)
}

\begin{abstract}
Anemia is a major health problem throughout the world with an annual prevalence of 400 million. The prevalence rates are higher in developing countries like India, especially affecting toddler, adolescents and women. Further women of child bearing age are more susceptible to have anemia because of various factors. The current study throws a light on the same issue. This descriptive study was conducted to assess the prevalence and knowledge of anemia among women of reproductive age group (15-49years) residing in rural Punjab. 40 reproductive age women of village Abhipur, Mohali, Punjab were randomly selected through lottery method for the study and interviewed with help of self structured validated tool. Feasibility and reliability of the tool was confirmed by conducting pilot study. Collected data was analyzed for descriptive and inferential statistics. The overall prevalence of anemia among women of reproductive age group was found to be $92.5 \%$ and about half of subjects were falling with mild $(10-11 \mathrm{gm} / \mathrm{dl})$ category of anemia. As per the knowledge part is concerned about 52.5\% were having average knowledge regarding anemia (causes, sign \& symptoms \& treatment).The overall mean score was 6.92. Age, education and working status of the females were found to have statistical significant association with the knowledge score related to anemia.
\end{abstract}

Key Words: Knowledge, prevalence, reproductive women, anemia

\section{Introduction}

Anemia is one of the most widespread nutritional deficiency disease and a major public health concern all over the world affecting all the ages and both gender. It is a one of the most prevalent health issue among women within reproductive age group. WHO has estimated that prevalence of anemia among reproductive age women is $14 \%$ in developed and 51\% in developing countries while it is $65-75 \%$ in India. (Mishra P 2012, Kalaivani K 2009, Barbara H, Rosenwei 2003)

Anemia is not a specific disease state but a sign of an underlying disorder. It is so far is a most common hematology condition. Anemia is a condition in which Hemoglobin concentration is lower than normal, reflects presence of fewer than normal RBCs with in circulation of oxygen delivered to body tissues. (NFHS-3, 200506, Park.k 2009, Umeta M, 2008)

Iron deficiency anemia is one of the commonest forms of anemia whose prevalence is high among reproductive age women. The main reason is excessive loss of iron or demand of iron associated with menstruation and child birth. It is a critical health concern as it effect growth, energy levels and also leads to various health problems. It is one of the main cause of morbidity, mortality in reproductive age and a key factor to low birth weight. Due to poverty, inadequate diet, pregnancy, lactation, poor educational level and poor access to health services women become an easy prey for anemia. (Bhanushali et al 2011, Kanani and Poojara, R.H. (1999) The reason for the high morbidity and mortality rates among women can be that the manifestations of anemia among women in reproductive age may not be noticeable easily in the beginning as it is like an ice berg. But Paleness, fatigue, low blood pressure can be manifested later. In severe cases, there will be shortness of breath and chest pain, which is an evidence of inadequate perfusion and oxygenation of the major organs. These factors can worsen the health conditions of women and lead to various secondary health problems such as lung diseases, cardiovascular diseases and heart attack, ultimately death. Whereas severe anemia is closely related to risk of high mortality even mild anemia carries health risks and reduces capacity to work. (Khatry J (2008), Jyoti S, lily P, Right K, Sujata. N. (2001), Sood S K et al. (1974)

Inspite of various programmes started by government of India, there is no significant decline in the prevalence of anemia. Still a large chunk of women falls into deadly jaws of anemia.

\section{Need Of The Study}

Anemia continues to be a major public health problem in India. Iron deficiency anemia occurs more often in women than in men, the main reason is excessive loss of iron or demand of iron associated with menstruation and child birth. Among the women also reproductive age women are at the highest risk for anemia as their requirements for iron are higher than any other group and they are most susceptible to associated health 
problems. The prevalence of anemia among women is as high as of $96.8 \%$ as reported by Mishra $\mathbf{P}$ (2012) in his study. P Malhotra, Savita kumari, R kumar and Varma S (2004) also reported prevlence of 55\% among women below 30 years of age.

More over the risk for anemia is further aggravated by poverty, illiteracy, ignorance and lack of knowledge regarding iron deficiency anemia. Most of the Indian women often take food left over by their husband. In some societies, men eat first and women last and poorly. This is increasing the burden of iron deficiency anemia among them.

The researcher during their clinical and community posting observed multiple cases of anemia in reproductive age and discovered that lack of appropriate knowledge about anemia and its prevention is one of the main cause for its high prevalence. Above all most of the women did not have easy access to health facilities and they were ignorant about their health status. So keeping this background in mind the researchers felt the need to conduct the present study assessing the prevalence and knowledge of anemia among the women of reproductive age group (15-49years).

\section{Objectives}

$>$ To assess the prevalence of anemia among women of reproductive age group.

$>$ To assess the Knowledge regarding anemia among women of reproductive age group.

$>$ To determine the significant relationship of prevalence and knowledge with selected sociodemographic variables.

\section{Assumptions}

$>$ Anemia is more prevalent among women of reproductive age group.

$>$ Women within reproductive age group will have some knowledge about anemia.

\section{Delimitations}

$>$ The study was delimited to the women in the age group of 15-49 years and who attained menarche.

$>$ Result of $\mathrm{Hb}$ estimation by telequest method only

\section{Methodology}

RESEARCH DESIGN: A descriptive survey approach was used in present study to assess the prevalence and knowledge regarding anemia among women of rural community Abhipur, Mohali (Punjab).

SAMPLE AND SAMPLING TECHNIQUE: Total of 40 women of reproductive age group (15-49years) were recruited through random sampling method. Initially a house to house survey was done to identify the women and then through lottery method desired sample of 40 women was chosen out by some another person who was not aware about the study.

DEVELOPMENT \& DESCRIPTION OF TOOL: By referring various textbooks, journals and network self structured tool was prepared which consisted of three parts:

Part I: It consisted of 8 items related to demographic profile of reproductive age women

Part II: It included 3 items related to prevalence of anemia i.e clinical signs of anemia and hemoglobin level which was checked using standardized WHO telequest sheet.

Part III: Structured knowledge questionnaire on anemia which included 16 questions related to anemia, its common cause, sign and symptoms of anemia, treatment \& prevention etc. Correct answer was given a score point of "one" and wrong answer was given score "zero". Maximum score of the questionnaire was 16. Scoring was categorized as follow:

Poor knowledge: 0-25\%

Average knowledge: $25-50 \%$

Good knowledge: $50-75 \%$

Excellent knowledge: $75-100 \%$

The content validity of the tool was established by taking opinion from nursing experts. Prior to main study a pilot study was conducted on 5 women of reproductive age group of different village of same area to find out reliability of the tool and feasibility of the study. Reliability of the tool was calculated by using Spearman Brown's Prophecy formula. Tool was found to be highly reliable with reliability of 0.93. Written permission was taken from the sarpanch of area and verbal consent was taken from the subjects before proceeding for the study. 
DATA COLLECTION: Data collection of the study was carried out on desired sample of 40 women. Prior to handing over the questionnaire to collect the data from subjects, investigator self introduced herself and explained the purpose of the study. Subjects were assured that their responses were kept confidential and will only be used for research purpose. On an average 30 minutes were taken by each subject to fill the questionnaire. Simultaneously health assessment of each subject was done to identify clinical signs of anemia i.e color of tongue, eyes, Capillary refilling time and $\mathrm{Hb}$ level. Hemoglobin level of women was checked by taking drop of blood on blotting paper and matching with standardized WHO telequest sheet and subsequently the levels of anemia are categorized as no anemia (>11 gm/dl), mild $(10-11 \mathrm{gm} / \mathrm{dl})$, moderate $(7-10 \mathrm{dm} / \mathrm{dl})$, severe $(<7 \mathrm{gm} / \mathrm{dl})$.

DATA ANALYSIS: The data collected was coded and entered in to master sheet. Descriptive (Frequency, \%, mean, S.D.) and inferential statistics (unpaired $t$ test) were used for data analysis.

\section{DEMOGRAPHIC PROFILE:}

\section{Results}

TABLE 1 depicts the socio demographic characteristics of the study subjects. It shows that maximum number $(52.5 \%)$ of subjects were from age group of $15-25$ years. Education wise $57.5 \%$ of respondent had studied up to secondary level whereas only $2.5 \%$ of respondent were graduate. Most of the women $(82.5 \%)$ were non - working. About half of the subjects had monthly income $\leq 5,000$ rupees and only $5 \%$ respondent had monthly income $\geq$ Rs 15,000 . Most of the women were from Sikh religion. $62.5 \%$ of respondent were married. Parity wise $35 \%$ had 2 children and about $37.5 \%$ had not conceived yet. About $70 \%$ of subjects came from joint type of family.

TABLE - 1: Percentage distribution of subjects as per demographic data $(\mathrm{N}=40)$

\begin{tabular}{|c|c|}
\hline Variable & $\mathrm{n}(\%)$ \\
\hline \multicolumn{2}{|l|}{ Age (in years) } \\
\hline $15-25$ & $21(52.5)$ \\
\hline $26-35$ & $14(35.0)$ \\
\hline 36 and above & $05(12.5)$ \\
\hline \multicolumn{2}{|l|}{ Education } \\
\hline Never attended school & $03(7.5)$ \\
\hline Primary & $13(32.5)$ \\
\hline Secondary & $23(57.5)$ \\
\hline Graduate and above & $1 \quad(2.5)$ \\
\hline \multicolumn{2}{|l|}{ Working status } \\
\hline Working & $07(17.5)$ \\
\hline Non-working & $33(82.5)$ \\
\hline \multicolumn{2}{|l|}{ Family income } \\
\hline$\leq 5,000$ & $20(50.0)$ \\
\hline$\overline{5}, 000-10,000$ & $13(32.5)$ \\
\hline $10,000-15,000$ & $05(12.5)$ \\
\hline$\geq 15,000$ & $02(5.0)$ \\
\hline \multicolumn{2}{|l|}{ Religion } \\
\hline Sikh & $34(85.0)$ \\
\hline Hindu & $04(10.0)$ \\
\hline Muslim & $02(5.0)$ \\
\hline \multicolumn{2}{|l|}{ Marital status } \\
\hline Unmarried & $14(35.0)$ \\
\hline Married & $25(62.5)$ \\
\hline Widowed & $01(2.5)$ \\
\hline \multicolumn{2}{|l|}{ No. of children } \\
\hline 0 & $15(37.5)$ \\
\hline 1 & $11(27.5)$ \\
\hline 2 and above & $14(35.0)$ \\
\hline \multicolumn{2}{|l|}{ Type of family } \\
\hline Nuclear & $12(30.0)$ \\
\hline Joint & $28(70.0)$ \\
\hline
\end{tabular}




\section{PREVALANCE OF ANEMIA:}

Results shows that $32.5 \%$ of women had previous history of anemia and only $17.5 \%$ of women were taking the iron supplement. Sign and symptoms wise more than half of the subjects (57.5\%) reported weakness, followed by fatigue (55\%), lethargy (47.5\%) and fainting episodes (17\%). According to clinical signs of anemia $65 \%$ of respondents had pallor skin, followed by $(37.5 \%)$ had pallor tongue, $(35 \%)$ had CRT $>3 \mathrm{sec}$ whereas only very small number of subjects $(7.5 \%)$ had spoon shaped nail. Maximum numbers of subjects $(47.5 \%)$ were falling under mild anemia category, whereas about $(37.5 \%)$ had moderate anemia and $(7.5 \%)$ had severe and no anemia respectively. (TABLE 2)

Table - 2: Frequency and percentage distribution of women of reproductive age group according to prevalence of anemia

$$
(\mathbf{N}=\mathbf{4 0})
$$

\begin{tabular}{ll}
\hline Variable & $\mathbf{n}(\%)$ \\
\hline Previous History of anemia & $13(32.5)$ \\
Yes & $27(67.5)$ \\
No & $7(17.5)$ \\
Taking any supplement & $33(82.5)$ \\
Yes & \\
No & $22(55.0)$ \\
Assessment of women for Anemia & $23(57.5)$ \\
Fatigue & $19(47.5)$ \\
Weakness & $7(17.0)$ \\
Lethargy & \\
Any episode of fainting & $26(65.0)$ \\
Clinical Sign of anemia & $15(37.5)$ \\
Pallor Skin & $3(7.5)$ \\
Pallor tongue & $14(35.0)$ \\
Spoon shaped nail & \\
CRT $>3$ sec. &
\end{tabular}

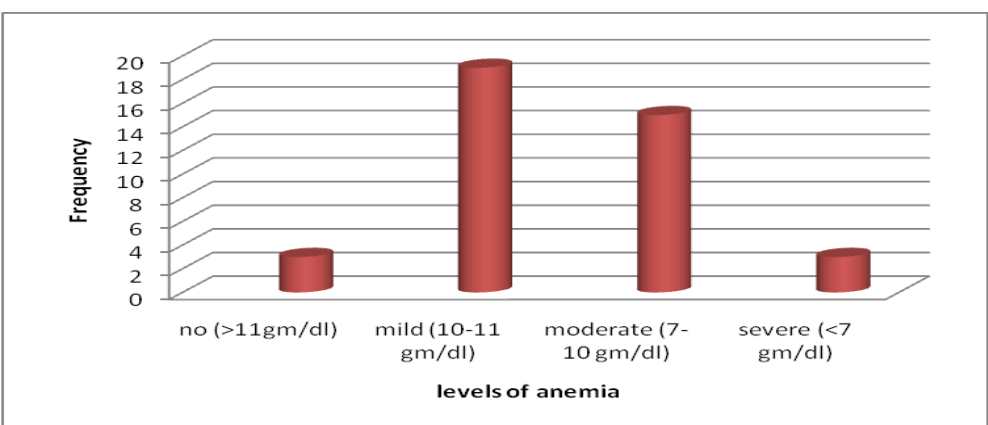

FIGURE 1: Frequency distribution of women according to levels of anemia $(\mathrm{Hb} \mathrm{gm} / \mathrm{dl})$

\section{KNOWLEDGE REGARDING ANEMIA AMONG WOMEN OF REPRODUCTIVE AGE GROUP:}

More than half of the sample had average knowledge regarding anemia, 33\% had good knowledge and about $15 \%$ had poor knowledge. There was not even a single woman with excellent knowledge regarding anemia.

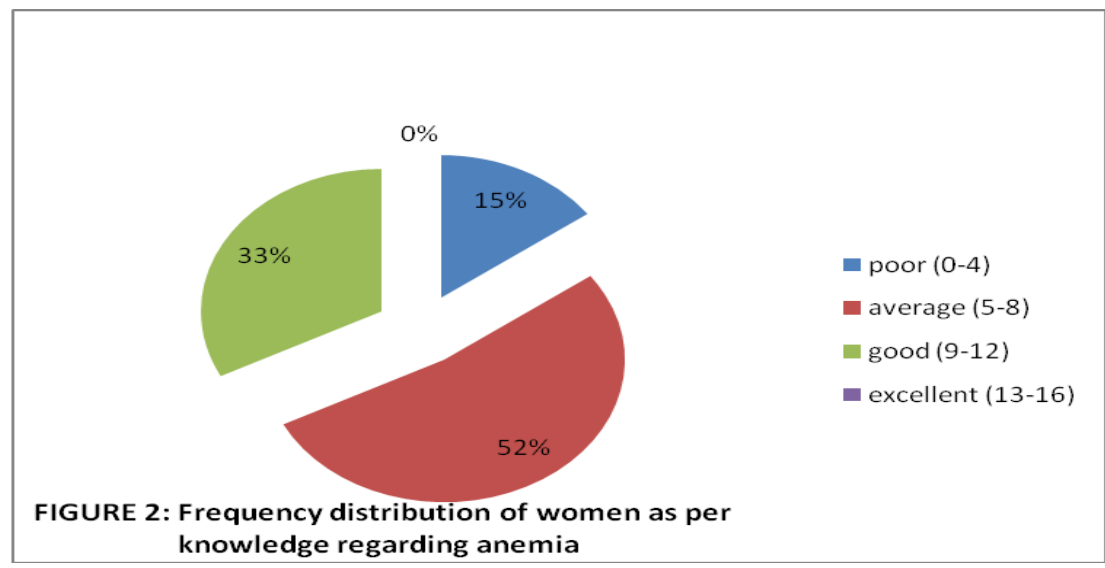




\section{MEAN KNOWLEDGE SCORES \& RELATIONSHIP OF KNOWLEDGE SCORE WITH SELECTED SOCIODEMOGRAPHIC VARIABLES:}

Overall mean knowledge score was $6.92 \pm 2.57$ with highest score of 12 . (TABLE 3). TABLE 4 depicts the relationship of knowledge scores with selected socio demographic variables. It has been seen that there is statistical significant relationship of knowledge score with age, education and working status of women. As the age increases knowledge also increases $(\boldsymbol{t}$ value $=5.28, \boldsymbol{p}$ level $=0.05,0.1)$. Education wise graduates had highest mean knowledge score of 12 whereas lowest mean score was 5.46 among the subjects who studied up to primary level only. The knowledge score of women according to the education was found to be statistically significant only for the subjects who never attended the school $(t$ value $=3.45, p$ level $=0.05,0.1)$ and who studied up to secondary level $(\boldsymbol{t}$ value $=1.72, \boldsymbol{p}$ level $=0.05)$. As per the working status of women is concerned highest mean score was 7.18 (non working women). The non working status had statistically significant relationship with the knowledge $(\boldsymbol{t}$ value $=1.90, \boldsymbol{p}$ level $=0.05$ ).

Regarding family income per month, highest mean knowledge score was 8.2 for category 10001-15000 Rupees whereas lowest mean score was 5.5 in category with monthly income $\geq 15000$ Rs. There was statistical significant relationship of knowledge score with family income $\leq 5000$ only ( $t$ value $=1.72$, $\boldsymbol{p}$ level $=0.05$ ).

The highest mean knowledge score for religion was 7.11 in Sikh category. The women falling under category of 0 or 1 child had mean knowledge score of 7.27. The relation of religion and no of children with knowledge score was found to be non significant.

Thus, it is evident that religion, and no of children had no significant relationship with knowledge, but age, education, working status and family income had impact on knowledge of anemia.

Table 3: Highest score, overall mean, mean \%, and S.D of knowledge score among women of reproductive age group.

$(\mathbf{N}=\mathbf{4 0})$

\begin{tabular}{lllll}
\hline Knowledge Score & Highest score & Mean & Mean \% & SD \\
\hline Overall value & 12 & 6.92 & 43.25 & 2.57 \\
\hline
\end{tabular}

TABLE 4: Significant relationship of prevalence and knowledge regarding anemia with selected socio Demographic variable.

$(\mathbf{N}=\mathbf{4 0})$

\begin{tabular}{|c|c|c|c|c|c|}
\hline \multirow{2}{*}{ Variables } & \multirow[t]{2}{*}{$\mathbf{n}$} & \multicolumn{3}{|c|}{ Knowledge score } & \multirow{2}{*}{ t value } \\
\hline & & Mean & Mean\% & SD & \\
\hline \multicolumn{6}{|l|}{ Age in years } \\
\hline $15-25$ & 21 & 9.43 & 58.94 & 3.07 & $2.07 *$ \\
\hline $26-35$ & 14 & 7 & 43.75 & 3.14 & $1.91 *$ \\
\hline 36 and above & 5 & 5.2 & 32.5 & 0.98 & $5.28 * *$ \\
\hline \multicolumn{6}{|l|}{ Education } \\
\hline Never attended & 3 & 8.33 & 52.06 & 0.94 & $3.45 * *$ \\
\hline Primary & 13 & 5.46 & 34.13 & 2.31 & $0.66^{\mathrm{NS}}$ \\
\hline Secondary & 23 & 7.09 & 59.08 & 2.37 & $1.72 *$ \\
\hline Graduate & 1 & 12 & 75 & 0 & - \\
\hline \multicolumn{6}{|l|}{ Working Status } \\
\hline Working & 7 & 5.71 & 35.69 & 1.66 & $1.90 *$ \\
\hline Non - Working & 33 & 7.18 & 44.88 & 2.64 & - \\
\hline \multicolumn{6}{|l|}{ Family Income } \\
\hline$\leq 5000$ & 20 & 6.3 & 39.3 & 2.65 & $1.72 *$ \\
\hline $5001-10000$ & 13 & 7.61 & 47.56 & 2.31 & $0.31^{\mathrm{NS}}$ \\
\hline $10001-15000$ & 5 & 8.2 & 51.25 & 4.07 & $1.48^{\mathrm{NS}}$ \\
\hline$\geq 15000$ & 2 & 5.5 & 34.38 & 0.5 & $1.31^{\mathrm{NS}}$ \\
\hline \multicolumn{6}{|l|}{ Religion } \\
\hline Sikh & 34 & 7.11 & 44.44 & 2.48 & $1.47^{\mathrm{NS}}$ \\
\hline Hindu & 4 & 5 & 31.25 & 2.74 & $0.49^{\mathrm{NS}}$ \\
\hline Muslim & 2 & 6 & 37.5 & 2.12 & $0.71^{\mathrm{NS}}$ \\
\hline \multicolumn{6}{|l|}{ No. of Children } \\
\hline 0 & 15 & 7.27 & 45.4 & 2.7 & $0.96^{\mathrm{NS}}$ \\
\hline 1 & 11 & 7.27 & 45.4 & 2.1 & $1.06^{\mathrm{NS}}$ \\
\hline 2 & 14 & 6.29 & 41.81 & 2.4 & $1.02^{\mathrm{NS}}$ \\
\hline
\end{tabular}

"Significant at p level<0.05, ** significant at p level <0.05 and 0.1, NS: Non significant 


\section{Discussion}

The aim of study was to assess the prevalence and knowledge regarding anemia among women of rural community of Punjab. 40 women were recruited for the study. Overall prevalence of anemia among women of reproductive age group was found to be $92.5 \%$ and about half of subjects were falling under mild $(10 \mathrm{gm} / \mathrm{dl})$ category of anemia. Similar results were reported in a study conducted by P Mishra (2012) where about 96.8\% of the subjects were anemic and majority of anemic women were in category of mild to moderate anemia. Manmeet kaur and Kamaljit Singh (2009) also conducted a similar kind of study in an urban area of Chandigarh and as per their result the overall prevalence of anemia among reproductive age women was $73.3 \%$. Another study carried out in Karnataka (NFHS 3-2005-06) also showed that prevalence anemia among rural reproductive age women was about $52.7 \%$.

As per the knowledge part is concerned about $52.5 \%$ of subject were having average knowledge regarding anemia (causes, sign \& symptoms \& treatment).The overall mean score was 6.92 . This result is quite different from the study conducted by Shweta Upadhya, A.R. Kumar, Rita Raguvanshi (2011) where the mean score 23.28. This difference can be due to small sample size of the present study.

As per the relationship of knowledge score (anemia) with selected socio demographic variables is concerned some of the variables were found to have significant relation with knowledge regarding anemia. The most striking factor, which came out to affect the knowledge of subjects on anemia was age, educational qualification and working status.

All the categories of age were found to have statistically significant relationship with knowledge. The subjects falling under age groups as 15-25 years have more access to the books and educational materials related to anemia which increase their knowledge. The more significant relationship was seen for age group 36-47 years at p levels 0.05 and 0.1 which says that with an increase in age knowledge also increases. The reason behind this can be the increased experience and education level of the women. The results are in accordance with the results of study conducted by Shweta Upadhyay, A. R. Kumar, Rita Singh Raghuvanshi and B. B. Singh (2011).

Educational qualification was also found to be significantly related with knowledge score. Women who never attended the school and the women who studied up to secondary level were seen having significant relationship with knowledge. This may be because of greater exposure to the information of the subjects with higher educational qualification. Mishra P et al. (2012) also reported that educational qualification is a key determinant which affects the knowledge of women regarding nutrition and anemia.

Working women were also had statistical significant relationship with the knowledge regarding anemia as working outside the home will give them an opportunity to interact with other, to explore and increase their knowledge regarding anemia. The other socio demographic variables such as family income, religion, no. of children did not have significant relationship with knowledge score.

\section{Conclusion}

Anemia remains a very common health problem among the women of reproductive age group and leads to high morbidity and mortality rates among females. Most of the women have poor knowledge regarding anemia, its cause, prevention and management. The current study was an attempt towards this side to estimate prevalence and knowledge regarding anemia among reproductive age women. The overall findings of the study show the high prevalence of anemia. There is need to improve the health care services, facilities and more importantly knowledge among the women on topics related to anemia and its prevention. More and more grass root level workers should be trained in this area so that they can provide services at the primary levels before the initiation of illness. Further more and more studies should be carried out in different parts of country to get an exact picture of anemia and based upon that practical approach should be adopted to eliminate the problem.

\section{NURSING PRACTICE:}

\section{IMPLICATIONS}

The population is increasing minute by minute but the basic resources supporting the life are declining day by day. Whether, we have improvements in various sectors but they are proving fruitful for growing population. As various health programmes are running over the country to combat anemia, nurses are the one who can contribute their drop of skillful efforts in the big ocean of such programmes. As a teacher nurse can provide teaching to people about the knowledge to improve the health status of the female, and prevention from anemia.

\section{NURSING EDUCATION:}

Since today's nursing students are tomorrow's staff nurse, educationists, administrators and supervisors, this study have implications in nursing education as well. Nursing teachers should emphasis on health education and methods of imparting education in the effective way during student training period. Students should get opportunity to give health education in an appropriate way during their clinical practice. 
Nursing education should emphasis more on preparing prospective nurses to impart information on anemia its causes, sign and symptoms, prevention and control.

\section{NURSING ADMINISTRATION:}

The concept of extended and expanded role of nurse offers many opportunities for a nurse administrator to improve the quality of life of women. The nurse administrator should co-ordinate her work along with the preventive, creative and rehabilitative aspect of care. The nursing administrators at various level of health care delivery system should focus their attention to make public conscious about anemia prevention.

\section{NURSING RESEARCH:}

One of the main aim of the nursing research is to contribute knowledge to the body of the nursing, to expand and broaden the scope of nursing. This is possible only if nurses are taking initiative to conduct further research. Research should be done to assess the magnitude of anemia in community and also to find out various innovative methods for effective teaching to improve the knowledge regarding anemia and its prevention. An idea about knowledge and prevalence rates of anemia will help the nurses to formulate effective strategies to combat this ice berg problem.

\section{RECOMMENDATIONS}

On the basis of findings of study, it is recommended that:

$>$ A study can be replicated on a larger sample thereby findings can be generalized for larger population.

$>$ A study can also be conducted among other age group.

$>$ A study can also be conducted in an urban community.

$>$ A study can be conducted for the future research to seek systematic way and interventions to establish a better understanding of anemia.

\section{References}

[1]. Barbara H, Rosenwei (2003). The nutrition transition is underway in India. J. Nutr. 131, 2692 -2700

[2]. Bhanushali, M. M., Shirode, A. R., Joshi, Y. M., and V.J. Kadam (2011). An intervention on iron deficiency anaemia and change in dietary behaviour among adolescent girls. International Journal of Pharmacy and Pharmaceutical Sciences, 3: 40-42.

[3]. Chaudhary SM, Dhage VR (2008). A Study of Anemia Among Adolescent Females in the Urban Area of Nagpur. Indian J Community Med. Oct 2008; 33(4): 243-245.

[4]. International Institute for Population Sciences (IIPS) \& Macro International (2007) National Family Health Survey 2005-06 (NFHS-3).

[5]. Jyoti S, lily P, Right K, Sujata. N. (2001). Anemia in adolescent girls: a preliminary report from urban Delhi. Indian Pediatr 2002; 39: 1126-30.

[6]. Kalaivani K (2009). Prevalence \& consequences of anaemia in pregnancy. Indian J Med Res 130: 627-633.

[7]. Kanani and Poojara, R.H. (1999). Supplementation with iron and folic acid enhances growth in adolescent Indian girls J. Nutr., $130,452 \mathrm{~S}-455 \mathrm{~S}$

[8]. Khatry J (2008). Study on sustainability of management of moderate anemia in pregnant women and its impact on birth weight dissertation for MD CHA submitted. University of Delhi, Delhi.

[9]. Kaur, M. and K. Singh (2001). "Effect of Health Education on Knowledge, Attitude and Practices About Anaemia Among Rural Women in Chandigarh." Indian Journal of Community Medicine, 26(3): 128-128.

[10]. Park.k (2009). Text book of preventive and social medicine: M/S banarsidas bhanot

[11]. Malhotra P, Kumari S, Kumar R, Varma S (2004). Prevelanvce anemia in adult rural population of north india. Journal of association of physicians of india. 52:18-20

[12]. Mishra P, Ahluwalia SK, Garg PK, Kar R, Panda GK (2012). The prevalence of Anemia among reproductive age group (15-45 years) women in a PHC of rural field area of MM Medical College, Ambala, India. J Women's Health Care. 1(3): 1-3

[13]. Sood SK, Ramachandran K, Mathur M, Gupta K, Ramalingswami V, et al (1974). WHO sponsored collaborative studies on nutritional anemias in India: the effect of supplemental oral iron administration to pregnant women. QJM. 44: 241-258

[14]. Upadhya S, Kumar AR, Raghuvanshi R and Singh BB (2011). Nutritional Status and Knowledge of Hill Women on Anemia: Effect of Various Socio-demographic Factors. J Hum Ecol. 33(1): 29-34

[15]. Umeta. M, Haider J, Demissie G, Akalu G, Ayana G (2008). Iron deficiency anemia among women of reproductive age in nine administrative regions of Ethiopia. Ethiop J Health Dev. 22(3): 252-8 